\title{
Antimicrobial Activity of Essential Oils of Lamiaceae Aromatic Spices Towards Sheep mastitis-Causing Staphylococcus aureus and Staphylococcus epidermidis
}

Maria Cristina Queiroga, Madalena Pinto Coelho, Sílvia Macedo Arantes, Maria Eduarda Potes \& Maria Rosário Martins

To cite this article: Maria Cristina Queiroga, Madalena Pinto Coelho, Sílvia Macedo Arantes, Maria Eduarda Potes \& Maria Rosário Martins (2018): Antimicrobial Activity of Essential Oils of Lamiaceae Aromatic Spices Towards Sheep mastitis-Causing Staphylococcus aureus and Staphylococcus epidermidis, Journal of Essential Oil Bearing Plants

To link to this article: https://doi.org/10.1080/0972060X.2018.1491330

冊 Published online: 15 Nov 2018.

Submit your article to this journal 저

View Crossmark data ־ 


\title{
Antimicrobial Activity of Essential Oils of Lamiaceae Aromatic Spices Towards Sheep mastitis-Causing Staphylococcus aureus and Staphylococcus epidermidis
}

\author{
Maria Cristina Queiroga ${ }^{1,2 *}$, Madalena Pinto Coelho ${ }^{1}$, Sílvia Macedo \\ Arantes ${ }^{2,3}$,Maria Eduarda Potes ${ }^{1,2}$, Maria Rosário Martins ${ }^{3,4}$ \\ ${ }^{1}$ Departamento de Medicina Veterinária, Escola de Ciências e Tecnologia, Universidade de Évora \\ ${ }^{2}$ ICAAM - Instituto de Ciências Agrárias e Ambientais Mediterrânicas, Universidade de Évora \\ ${ }^{3}$ Departamento de Química, Escola de Ciências e Tecnologia, Universidade de Évora \\ ${ }^{4}$ Laboratório HERCULES, Universidade de Évora, Evora 7000-809, Portugal
}

Received 15 August 2017; accepted in revised form 05 February 2018

\begin{abstract}
Mastitis in ewes is responsible for massive economic losses. Antibiotics are routinely used for mastitis control but its excessive use leads to development of antibiotic resistance with deleterious outcomes both for animal and public health. Essential oils (EOs) show antibacterial proprieties and no resistance has been reported after prolonged exposure; however their efficacy depends on their chemical composition. In this study EOs chemical composition from four autochthonous aromatic herbs, from Alentejo region, southern Portugal, Calamintha nepeta subsp. nepeta, Lavandula stoechas subsp. luisieri, Rosmarinus officinalis and Thymus mastichina was accessed. EOs of $R$. officinalis showed predominance in monoterpene hydrocarbons (63 \%) whereas EOs of T. mastichina, L. luisieri and C. nepeta were rich in oxygenated monoterpenes (71-95 $\%)$. The antimicrobial activity of selected EOs was investigated towards Staphylococcus aureus $(\mathrm{n}=24)$ and Staphylococcus epidermidis isolates $(n=24)$ from ovine mastitic milk origin. Results of disk diffusion assay revealed that $C$. nepeta, L. luisieri and T. mastichina EOs are highly active against both S. aureus and $S$. epidermidis strains, whereas $R$. officinalis EO is highly active against $S$. aureus strains but inactive against several S. epidermidis isolates. EOs concentration causing bacterial growth inhibition ranged from 500 to $4,000 \mu \mathrm{g} \mathrm{mL}^{-1}$ in liquid microassays.
\end{abstract}

Key words: Essential oils, antimicrobial activity, ovine mastitis, Staphylococcus aureus, Staphylococcus epidermidis.

\section{Introduction}

Sheep milk production in Alentejo region, southern of Portugal, is mostly intended for the manufacture of artisanal cheeses, which constitute a heritage to the region and add value to the production of this raw material. For cheese production, the milk must hold certain physicochemical, biochemical and microbial features only found in milk from healthy mammary glands.

Mastitis in ewes is responsible for significant economic losses due to the death and early cull- ing of animals ${ }^{1}$, poor lamb growth and survival ${ }^{2}$, lower milk yield ${ }^{3}$ and lower milk quality ${ }^{4}$. As subclinical mastitis is asymptomatic, milk from affected animals enters cheese production resulting in lower cheese production ${ }^{3,5}$ and worse quality ${ }^{6}$.

Species of Staphylococci are the main etiological agents of ruminant mastitis. Coagulase negative Staphylococci showed to be the most prevalent agents of clinical and subclinical mastitis in ewes in Alentejo, with special relevance to Sta-

*Corresponding author (Maria Cristina Queiroga)

E-mail: < crique@uevora.pt, cristina.queiroga@gmail.com >

(c) 2018, Har Krishan Bhalla \& Sons 
phylococcus epidermidis ${ }^{7}$. In the same study, also Staphylococcus aureus was isolated from cases of both clinical and subclinical mastitis. This fact is particularly important as a public health concern, as $S$. aureus is an important enterotoxin producer ${ }^{8}$.

Antibiotics are routinely used for mastitis control ${ }^{9}$. Nevertheless this practice is responsible for selection pressure for antibiotic-resistant strains, the main factor in development of antibiotic resistance ${ }^{10}$. Antimicrobial resistance genes have been detected in mastitis pathogens isolated from sheep ${ }^{11}$ and the presence of these resistant strains in dairy products may lead to antibiotic resistance genes transfer to human intestinal indigenous microbiota ${ }^{12}$.

Nowadays consumer demands regarding food safety requirements restrict the food presence of compounds used in animals' treatment. Therefore is appropriate to search for alternative substances that do not endanger consumer safety and contribute to the improvement of animal health.

Natural products as essential oils (EOs) and herbal extracts are currently used in medicine and food industry for their antimicrobial activities ${ }^{13}$. EOs are classified as GRAS (generally recognized as safe), show antibacterial proprieties and resistance has not been reported after prolonged exposure. Previous investigation of some EO antimicrobial activity against Staphylococcus spp. isolated from bovine mastitis showed that they may be considered as alternative candidates in mastitis therapy ${ }^{14}$.

The aim of this study was to investigate the antimicrobial properties of EOs of four Lamiaceae aromatic herbs, autochthonous from Portugal and used in Mediterranean diet, namely Calamintha nepeta subsp. nepeta (L.) Savi, Lavandula stoechas subsp. luisieri (Rozeira) Rozeira, Rosmarinus officinalis L. and Thymus mastichina L., towards important etiological agents of ovine mastitis, S. aureus and S. epidermidis.

\section{Materials and methhod \\ Essential oils preparation}

For the preparation of plant essential oils, leaves of Calamintha nepeta subsp. nepeta (calamint) and Lavandula stoechas subsp. luisieri (lavender) were collected in spring at Évora region, Alentejo. All plants were identified and voucher specimens were kept at the Herbarium of the University of Évora. After harvested, manual weeding of plants was done in order to obtain only the good parts of plants and eliminate the parts that could affect oil purity or interfere in oil pharmacological activity. The aerial parts of plants were air-dried in a dark room for 3 days. Essential oils of leaves from the plants studied were obtained by hydrodistillation for $3 \mathrm{~h}$ in a modified Clevenger-type apparatus, according to the European Pharmacopoeia method ${ }^{15}$. After extraction, the oils were stored at $-20^{\circ} \mathrm{C}$.

Essential oils of Rosmarinus officinalis (rosemary) and Thymus mastichina (thyme) were provided by ERVITAS CATITAS, a local company that produce EOs from cultivated plants by biological agricultural practices.

\section{Essential oils chemical characterization}

Chemical characterization of EOs was performed by gas chromatography with an ionization flame detector (GC-FID). Analysis was completed on HP-5890 SERIES II equipped with 30 $\mathrm{m} \times 0.25 \mathrm{~mm}$ i.d. $\mathrm{x} 0.25 \mu \mathrm{m}$ Supelcowax ${ }^{\mathrm{TM}} 10$ fused-silica polar capillary column (Supelco, Milford, USA) and ChemStation HP software, version A.04.02. The experiments were conducted under the following conditions: oven temperature programme, $70^{\circ} \mathrm{C}(3 \mathrm{~min}), 70^{\circ}-220^{\circ} \mathrm{C}\left(3^{\circ} \mathrm{C} / \mathrm{min}\right)$ and $220^{\circ} \mathrm{C}(5 \mathrm{~min})$; carrier gas flow rate $0.6 \mathrm{~mL}$ $\mathrm{He} / \mathrm{min}$; injector and detector temperatures $250^{\circ} \mathrm{C}$, injection volume $0.2 \mu \mathrm{L}$ and split ratio 50:1.

The different components of EOs were identified by their retention indices, calculated using linear interpolation relative to retention times of C8 - C22 of n-alkanes, were compared with those of individual standards and data from the literature ${ }^{16-18}$. The quantification of compounds was performed using relative percentage abundance on the basis of their GC peak areas without correction factors, and percentage was determined with the mean value of three injections of each sample.

\section{Bacterial isolates}

The antimicrobial screening of essential oils was 
performed by agar disk diffusion method against bacterial isolates from mastitic sheep milk origin, Staphylococcus aureus $(\mathrm{n}=22)$ and Staphylococcus epidermidis $(\mathrm{n}=22)$, with different profiles of antibiotic susceptibility, two S. aureus reference strains, ATCC 25923 and ATCC 29213, and two S. epidermidis reference strains, ATCC RP62A and ATCC 12228. Microbial isolates used in this study are deposited on the biobank of the Laboratory of Microbiology, Department of Veterinary Medicine, University of Évora and were isolated during a sheep mastitis survey ${ }^{7}$.

Minimal inhibitory concentration (MIC) and minimum bactericidal concentration (MBC), determined using the broth micro-dilution method, were assayed against eight randomly chosen isolates of each two Staphylococcus species.

Bacterial inoculum were prepared by growing cells in blood agar (Blood Agar Base $\mathrm{N}^{\circ} 2, \mathrm{CM}$ 0271 with $5 \%$ sheep blood, Oxoid, England) for $24 \mathrm{~h}$ at $37^{\circ} \mathrm{C}$. A cell suspension was prepared in MHB (Mueller-Hinton broth, CM 0405, Oxoid, England) to a final concentration of $10^{8} \mathrm{CFU}$ $\mathrm{mL}^{-1}$ for the disk diffusion assay and $10^{6} \mathrm{CFU}$ $\mathrm{mL}^{-1}$ for the broth dilution assay ${ }^{19,20}$.

\section{Agar disk diffusion assay}

Agar disk diffusion assay was performed in accordance with CLSI Performance Standards for Antimicrobial Disk Susceptibility Tests ${ }^{19}$. For the evaluation of antimicrobial activity, MHA (Mueller-Hinton agar, CM0337, Oxoid, England) plates were inoculated with a sterile swab in three different directions, so that the inoculum was well distributed throughout the medium surface. Then three paper sterile disks were placed on each plate and $5 \mu \mathrm{L}$ of EO was added. The assay was performed in triplicate for each EO. The plates were then incubated at $37^{\circ} \mathrm{C}$ for 24 hours, after which the diameter of the inhibition zone was measured. EOs were classified as highly active if the diameter of inhibition zone was greater than $8 \mathrm{~mm}$, moderately active if the diameter was between 6 and $8 \mathrm{~mm}$ and inactive if the diameter was less than $6 \mathrm{~mm}$.

\section{Broth microdilution assay}

To determine minimal inhibitory concentration
(MIC) of EOs, broth microdilution assay was performed according to CLSI methods for dilution antimicrobial susceptibility tests for bacteria that grow aerobically ${ }^{20}$. EOs were diluted in MHB containing $5 \%$, v/v DMSO (dimethyl sulfoxide, D-8418, Sigma, USA) and $2.5 \%$ v/v Tween 80 (polyoxyethylene-sorbitan monooleate, P-1754, Sigma, USA). Fifty microliters of each dilution were placed into 96 -well plates and $50 \mu \mathrm{L}$ of a bacterial suspension were added and the inhibitory action was assessed for the concentrations ranging $125-4,000 \mu \mathrm{g} \mathrm{mL}^{-1}$. For growth control (positive control) $50 \mu \mathrm{L}$ of MHB containing DMSO $(5 \%, v / v)$ and Tween $(2.5 \%, v / v)$ with $50 \mu \mathrm{L}$ of a bacterial suspension was used and 100 $\mu \mathrm{L}$ of MHB with DMSO (5\%, v/v) and Tween $(2.5 \%, \mathrm{v} / \mathrm{v})$ comprised the sterility control (negative control). All experiments were performed in triplicate. The plates were incubated at $37^{\circ} \mathrm{C}$ for 16 to 20 hours and bacterial growth was detected by the unaided eye observation. MIC was defined as the lowest concentration of antimicrobial agent that completely inhibits growth of the organism in the microdilution wells.

To determine the minimum bactericidal concentration (MBC), all cultures showing no turbidity were sub-cultured. Ten microliters from wells without bacterial growth were inoculated in the surface of MHA plates, in triplicate, and incubated at $37^{\circ} \mathrm{C}$ for 24 hours. The MBC was defined as the lowest concentration of EO that did not show bacterial growth ${ }^{14}$.

\section{Results and discussion}

The chemical composition of crude essential oils is summarized in Table 1, reporting their main volatile components and respective percentage content. GC-FID analyses of each EO allowed the identification and quantification of its components. The composition of the EOs tested was very different among them, especially in what regards to their major components. EOs C. nepeta, L. luisieri and T. mastichina were rich in oxygenated monoterpenes whereas $R$. officinalis showed predominance of hydrocarbon monoterpenes.

The main components of EOs were isopulegol (43.0\%), isopulegone (15.6\%) and 1,8-cineole (14.4\%) for C. nepeta; 1,8-cineole (18.8\%) and 
Table 1. Chemical composition of studied essential oils

\begin{tabular}{|c|c|c|c|c|c|c|}
\hline \multirow[b]{2}{*}{ Components } & \multirow[b]{2}{*}{$\mathbf{R I}_{\text {cal }}^{\mathrm{a}}$} & \multirow[b]{2}{*}{$\mathbf{R I}$} & \multicolumn{4}{|c|}{$\%$ Area } \\
\hline & & & $\begin{array}{c}\text { Calamintha } \\
\text { nepeta }\end{array}$ & $\begin{array}{l}\text { Lavandula } \\
\text { luisieri }\end{array}$ & $\begin{array}{c}\text { Rosmarinus } \\
\text { officinalis }\end{array}$ & $\begin{array}{l}\text { Thymus } \\
\text { mastichina }\end{array}$ \\
\hline$\alpha$-Pinene & 1027 & $1029^{c}$ & 0.5 & 1.2 & 31.9 & 4.4 \\
\hline Camphene & 1063 & $1073^{b}$ & 0.1 & - & 8.1 & - \\
\hline$\beta$-Pinene & 1119 & $1116^{b}$ & 1.0 & 4.5 & 4.0 & 10.8 \\
\hline$\beta$-Myrcene & 1157 & $1161^{b}$ & 0.6 & - & 4.7 & 1.1 \\
\hline Limonene & 1202 & $1205^{b}$ & 1.4 & - & 11.2 & 1.7 \\
\hline 1,8-Cineole & 1215 & $1215^{b}$ & 14.4 & 18.8 & 17.6 & 55.9 \\
\hline$\gamma$-Terpinene & 1253 & $1251^{b}$ & - & & 1.8 & 1.2 \\
\hline p-Cymene & 1265 & $1273^{b}$ & 0.2 & - & 0.9 & 0.4 \\
\hline$\alpha$-Terpinolene & 1286 & $1287^{\mathrm{d}}$ & - & - & - & 1.2 \\
\hline Fenchone & 1404 & $1401^{c}$ & - & 1.9 & - & - \\
\hline Menthone & 1463 & $1461^{d}$ & 5.4 & - & - & - \\
\hline Isomenthone & 1487 & $1488^{\mathrm{e}}$ & 6.3 & - & - & - \\
\hline Camphor & 1514 & $1515^{b}$ & - & 1.1 & 7.4 & 0.1 \\
\hline Linalol & 1540 & $1542^{b}$ & - & 4.1 & - & 3.9 \\
\hline Isopulegol & 1560 & $1557^{\mathrm{e}}$ & 43.0 & - & - & - \\
\hline Isopulegone & 1575 & $1578^{\mathrm{e}}$ & 15.6 & - & - & - \\
\hline trans-Necrodyl acetate & 1590 & $1590^{\mathrm{c}}$ & - & 15.6 & - & - \\
\hline E-Caryophyllene & 1593 & $1594^{\mathrm{e}}$ & 0.4 & 6.0 & 2.3 & 0.5 \\
\hline Terpinene-4-ol & 1600 & $1599^{c}$ & 1.2 & 3.6 & 1.0 & 0.2 \\
\hline Lavandulyl acetate & 1602 & $1602^{c}$ & - & 3.3 & - & - \\
\hline cis-Necrodyl acetate & 1612 & $1611^{\mathrm{c}}$ & - & 1.2 & - & - \\
\hline allo-Aromadendrene & 1636 & $1637^{b}$ & & - & - & 1.4 \\
\hline Isoborneol & 1636 & $1665^{b}$ & - & 10.0 & 1.3 & - \\
\hline Pulegone & 1643 & $1640^{d}$ & 7.0 & - & - & - \\
\hline trans-necrodol & 1655 & $1657^{\mathrm{c}}$ & - & 10.1 & - & - \\
\hline Lavandulol & 1670 & $1668^{\mathrm{c}}$ & - & 11.0 & - & - \\
\hline$\alpha$-Terpinyl acetate & 1682 & $1692^{b}$ & - & 0.6 & - & 4.9 \\
\hline$\alpha$-Terpineol & 1700 & $1694^{\mathrm{c}}$ & 1.3 & 2.6 & 0.8 & 4.3 \\
\hline Borneol & 1702 & $1696^{\mathrm{c}}$ & - & 1.2 & 3.8 & 1.4 \\
\hline Verbenone & 1704 & $1698^{b}$ & - & - & 1.8 & - \\
\hline Caryophyllene oxide & 1970 & $1969^{b}$ & - & 0.6 & - & - \\
\hline Viridiflorol & 2071 & $2068^{c}$ & - & 1.5 & - & - \\
\hline Total identified & & & 98.4 & 98.9 & 98.6 & 93.4 \\
\hline Groups of components & & & & & & \\
\hline Monoterpene hydrocarbons & & & 3.8 & 5.7 & 62.6 & 20.8 \\
\hline Oxygenated monoterpenes & & & 94.2 & 85.1 & 31.9 & 70.7 \\
\hline Sesquiterpene hydrocarbon & & & 0.4 & 6.0 & 2.3 & 1.9 \\
\hline Oxygenated sesquiterpenes & & & & 2.1 & 1.8 & \\
\hline
\end{tabular}

${ }^{a}$ Retention indices relative to $\mathrm{C} 8-\mathrm{C} 22 \mathrm{n}$-alkanes on the Supelcowax ${ }^{\mathrm{TM}} 10$ column.

${ }^{b, c, d}$ Retention indices reported by literature: ${ }^{b}$ Cavaleiro et al. (2004); ${ }^{\mathrm{c}}$ Zuzarte et al. (2012); ${ }^{\mathrm{d}}$ Mortram

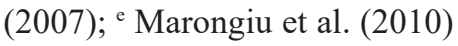


trans- $\alpha$-necrodyl acetate $(15.6 \%)$, lavandulol $(11.0 \%)$ and trans-necrodol $(10.1 \%)$ for $L$. luisieri; $\alpha$-pinene (31.9\%), 1,8-cineole (17.6\%), limonene (11.2\%) for $R$. officinalis and 1,8-cineole $(55.9 \%)$ and $\beta$-pinene $(10.8 \%)$ for $T$. mastichina.

According to disk diffusion assay, lavender and thyme EOs showed better inhibition activity for $S$. aureus isolates while calamint and lavender EOs exhibited greater activity for $S$. epidermidis isolates (Fig. 1 and 2).

Thyme EO evidenced to be highly active against all $S$. aureus isolates. The less active EO against this species isolates was rosemary EO, still it was strongly active against 16 isolates. Meanwhile, EOs of calamint and lavender, the most active against isolates of $S$. epidermidis, were both highly active against 23 isolates. Rosemary oil was poorly active against $S$. epidermidis isolates, being inactive against 18 isolates.

Results of broth dilution assay are summarized in Table 2 together with the inhibition zone on disk diffusion assay corresponding to each EO. The MIC value for the different EOs ranged from $500 \mu \mathrm{g} \mathrm{mL}^{-1}$ to $4,000 \mu \mathrm{g} \mathrm{mL} \mathrm{mL}^{-1}$ (Table 2).

Overall, isolates of $S$. epidermidis showed to be more resistance to EOs than the isolates of $S$. aureus. Nine combinations of $S$. epidermidis isolate/ EO showed no inhibition, as bacteria were not inhibited with $4,000 \mu \mathrm{g} \mathrm{mL} \mathrm{mL}^{-1} \mathrm{EO}$, while for $S$. aureus isolates, this happened for only four of the isolate/ EO cases.

Calamint displayed MIC values for S. aureus ranging from 500 to $4,000 \mu \mathrm{g} \mathrm{mL}^{-1}$ and for $S$. epidermidis from 2,000 to $4,000 \mu \mathrm{g} \mathrm{mL}^{-1}$. However, by disk diffusion assay, this EO was highly

Staphylococcus aureus

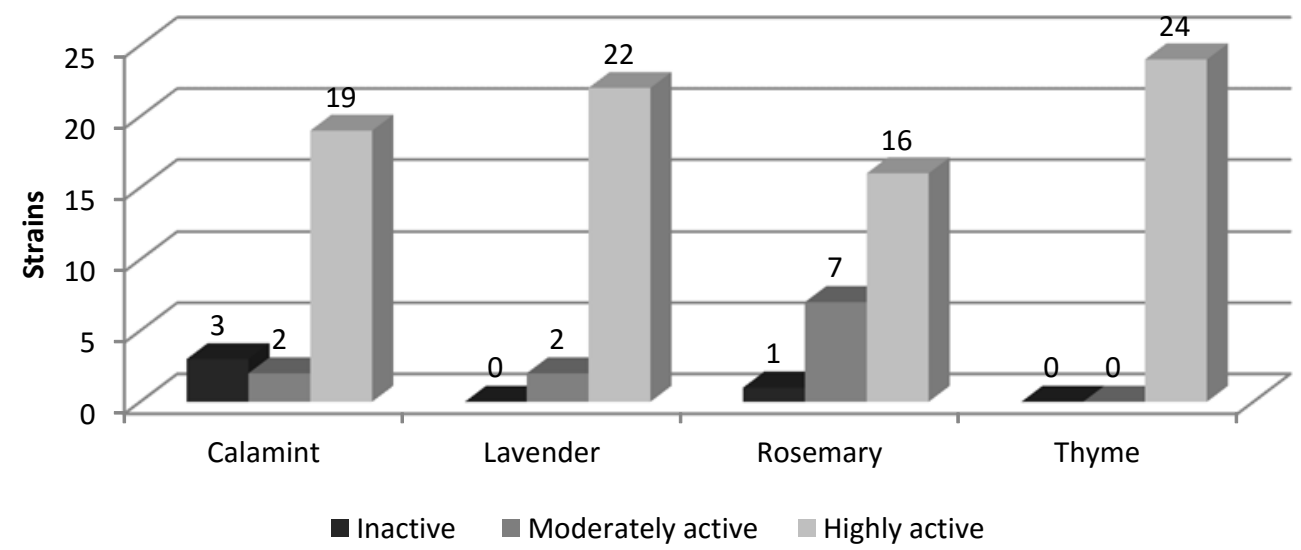

Figure 1. EOs disk diffusion assay antimicrobial activity against S. aureus

Staphylococcus epidermidis

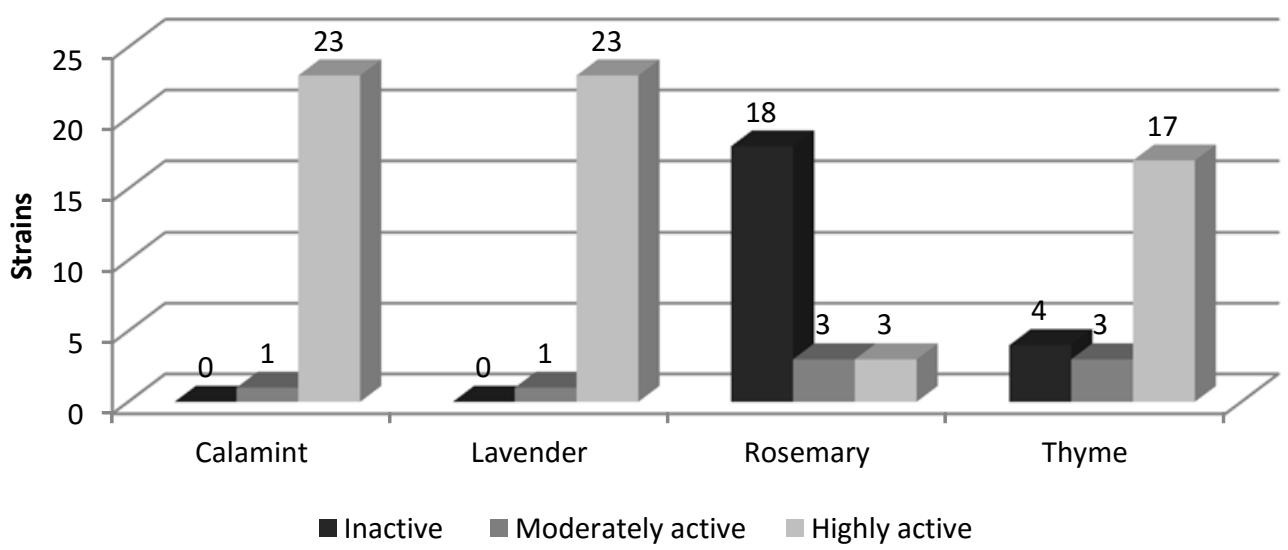

Figure 2. EOs disk diffusion assay antimicrobial activity against S. epidermidis 


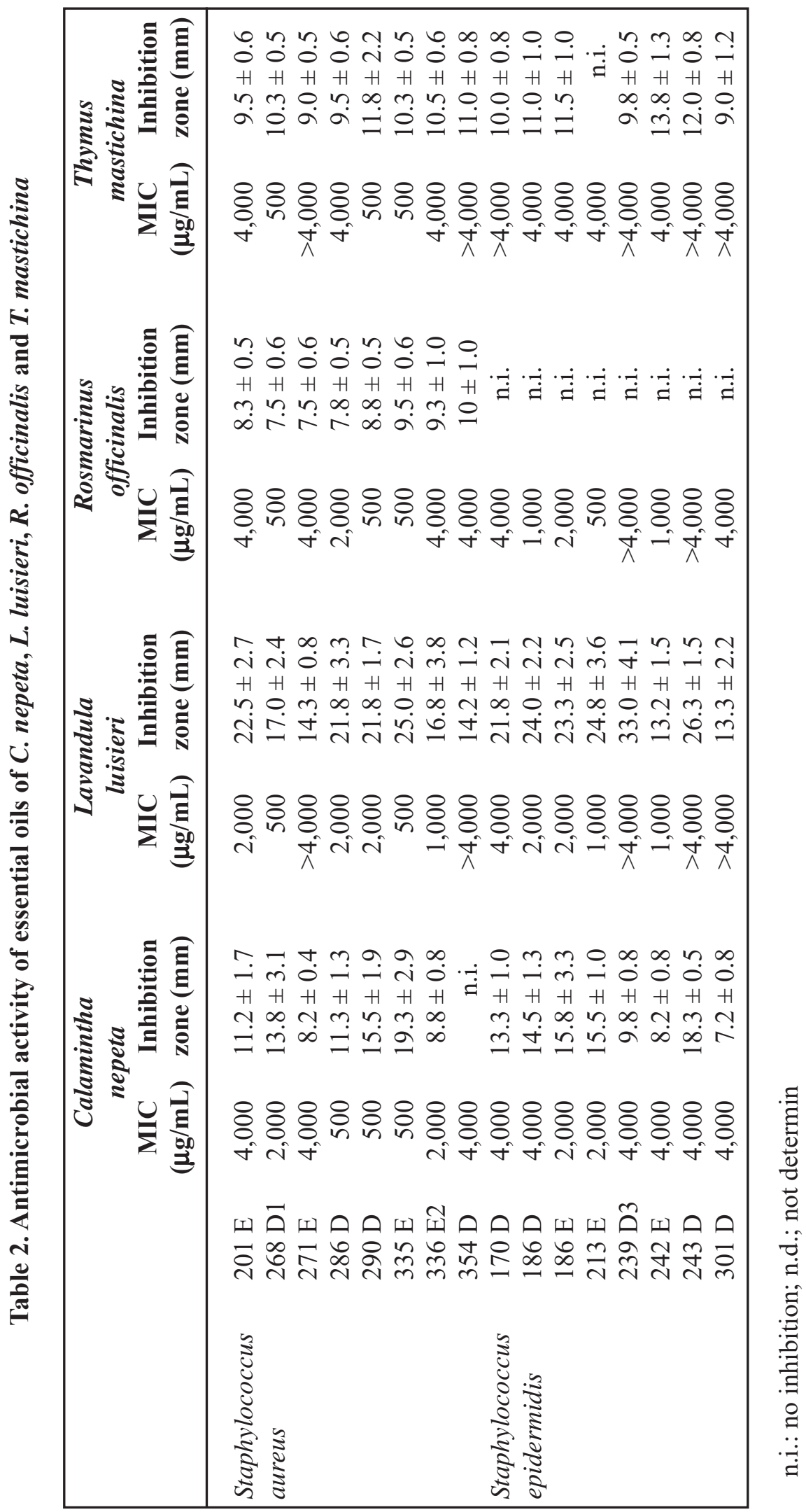


active against 19 S. aureus isolates and for $23 \mathrm{~S}$. epidermidis isolates, exhibiting high antimicrobial potential for these Gram-positive microorganisms, some of them very resistant to commercial antimicrobial compounds.

Lavander MIC for S. aureus was between 500 and $>4,000 \mu \mathrm{g} \mathrm{mL}^{-1}$. This EO, though, showed excellent results on the disk diffusion assay displaying high activity towards 22 isolates, with zone inhibition areas ranging from 14.2 to $25 \mathrm{~mm}$. For S. epidermidis isolates, Lavender MIC value ranged from 1,000 to $>4,000 \mu \mathrm{g} \mathrm{mL}^{-1}$, yet, on disk diffusion was highly active for 23 isolates, revealing zone inhibition areas between 13.2 and $33 \mathrm{~mm}$. Other authors also report good antimicrobial activity for this EO. A study of Lai et al. ${ }^{21}$, in which different organic extracts from Portuguese plants were evaluated for their antimicrobial potential, highlights $L$. luisieri extracts MIC values ranging between 15 and $250 \mu \mathrm{g} \mathrm{mL}^{-1}$ for $S$. aureus and 62 and $250 \mu \mathrm{g} \mathrm{mL}^{-1}$ for S. epidermidis. Arantes et al. ${ }^{22}$ reported the high activity of $L$. luisieri EO against a wide spectrum of microorganisms, such as Gram-positive and Gram-negative bacteria, with MIC values ranging between 150 and $1,000 \mu \mathrm{g} \mathrm{mL}^{-1}$.

Rosemary inhibited bacterial growth at concentrations between 500 and $4,000 \mu \mathrm{g} \mathrm{mL}^{-1}$ or higher, depending on the species, $S$. aureus or $S$. epidermidis. Also in disk diffusion assay the results were not very satisfying, as it was inactive for 18 S. epidermidis isolates. Likewise, Nascimento et al. ${ }^{23}$ reported no antimicrobial properties in a disk diffusion test for rosemary EO, and Dal Pozzo et al. ${ }^{14}$ stated that this EO showed no activity against Staphylococcus spp.. However, in other studies, rosemary EO was effective against Staphylococcus spp. ${ }^{11,24,25}$.

Thyme MIC results were between 500 and $>4,000 \mu \mathrm{g} \mathrm{mL}^{-1}$ for $S$. aureus, but, again, as to disk diffusion test it was highly effective for the totality of $S$. aureus isolates and for 17 of $S$. epidermidis isolates. Opposing to these results, Nascimento et al. ${ }^{23}$ reported that Thymus vulgaris EO shows no antimicrobial properties in a disk diffusion assay, but according to Mohsenzadeh ${ }^{26}$, the same thyme species EO has good activity against S. aureus, with a MIC of 10 to $100 \mu \mathrm{g}$ $\mathrm{mL}^{-1}$. Although the species of thyme used in this study was not the same, rendering to Faleiro et al. ${ }^{27}$, the antimicrobial activity of EOs from different Thymus species collected in Portugal are comparable to other studies results on thyme EOs from mediterranean species ${ }^{28}$.

Figure 3 to 6 underline the association between the results of the two tests. According to these results, there is no evidence of correlation between the zone of inhibition in the disk diffusion method

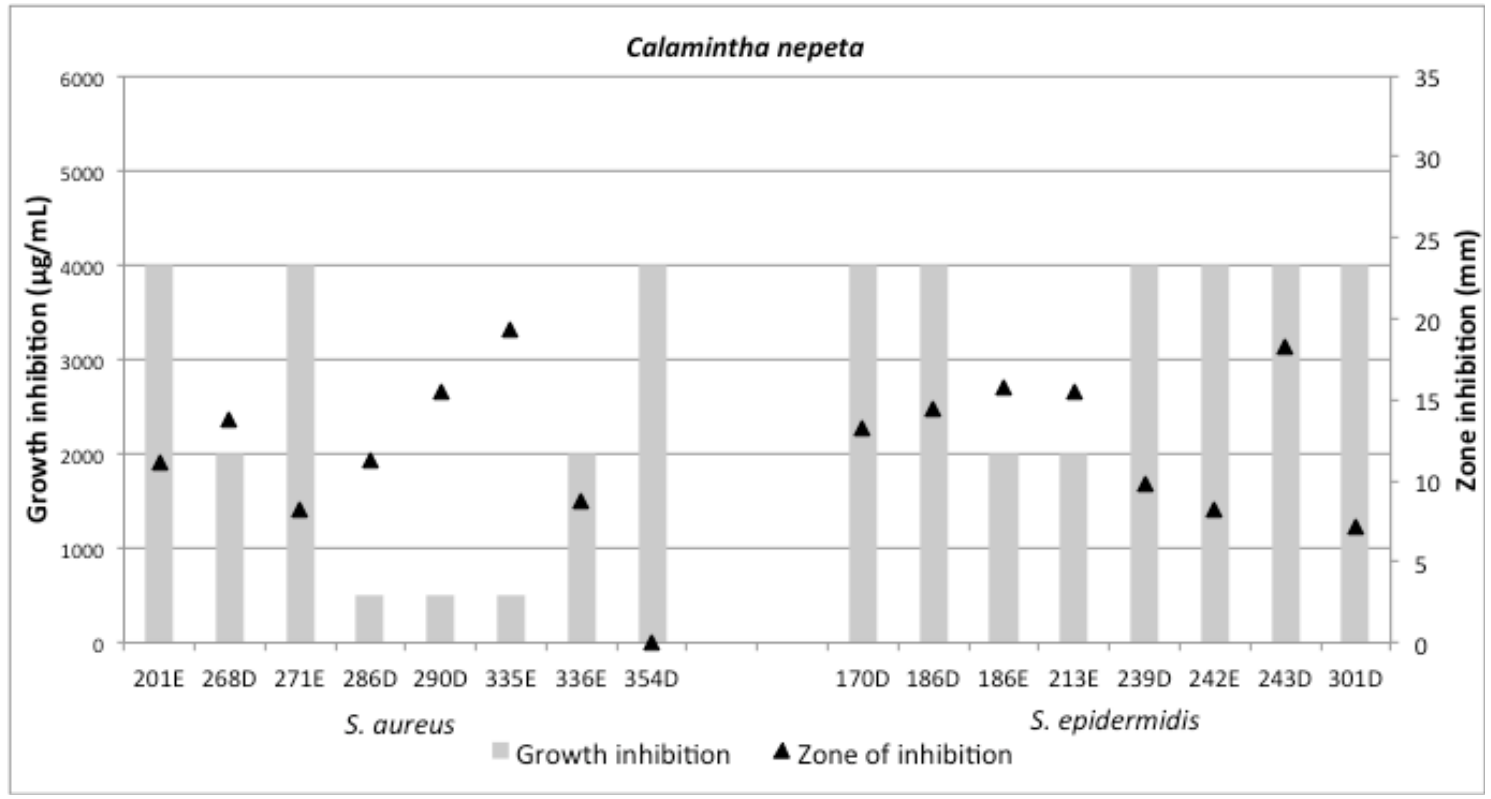

Figure 3. Calamint antimicrobial activity according to microdilution assay and disk diffusion method 


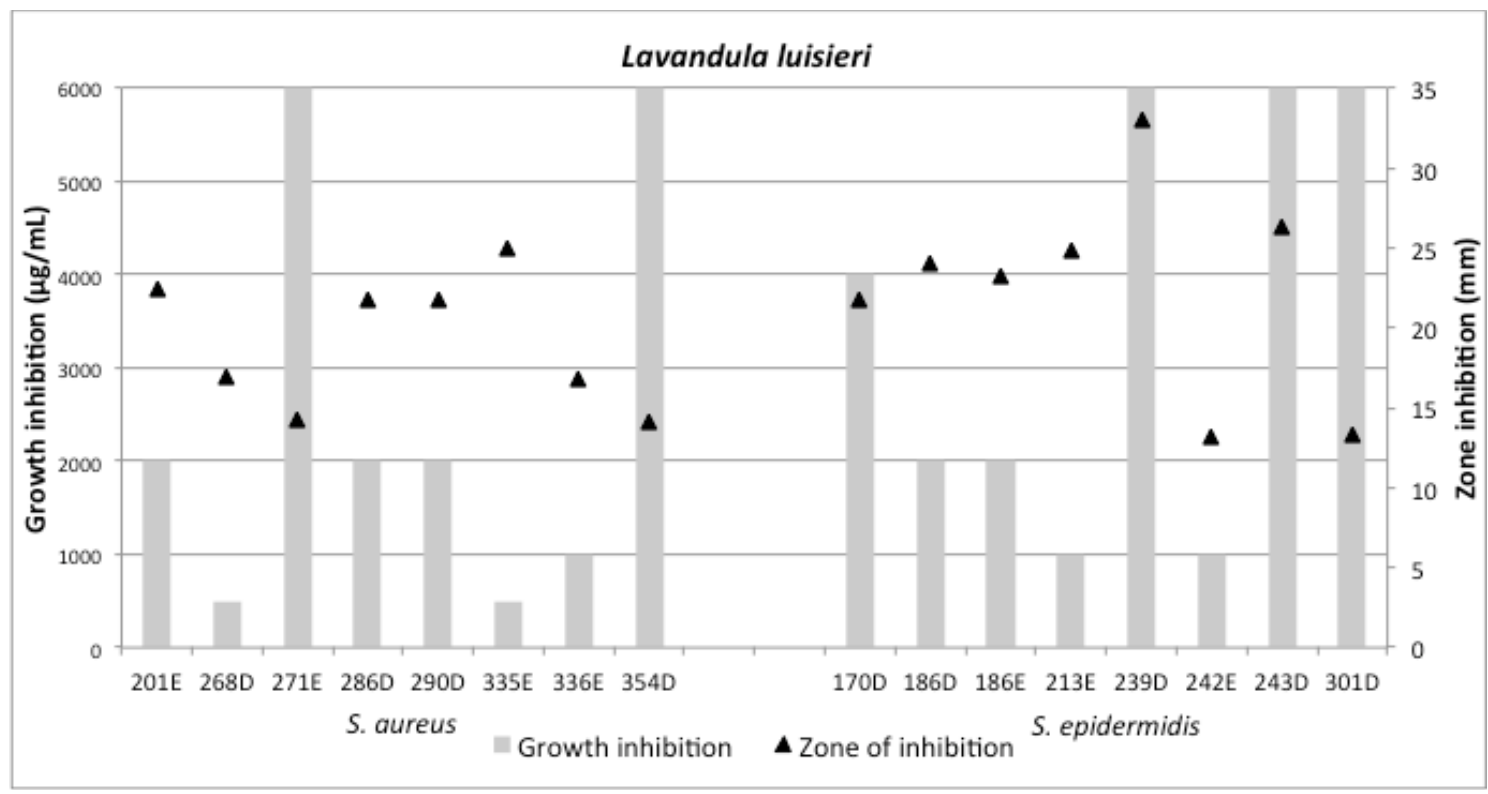

Figure 4. Lavender antimicrobial activity according to microdilution assay and disk diffusion method

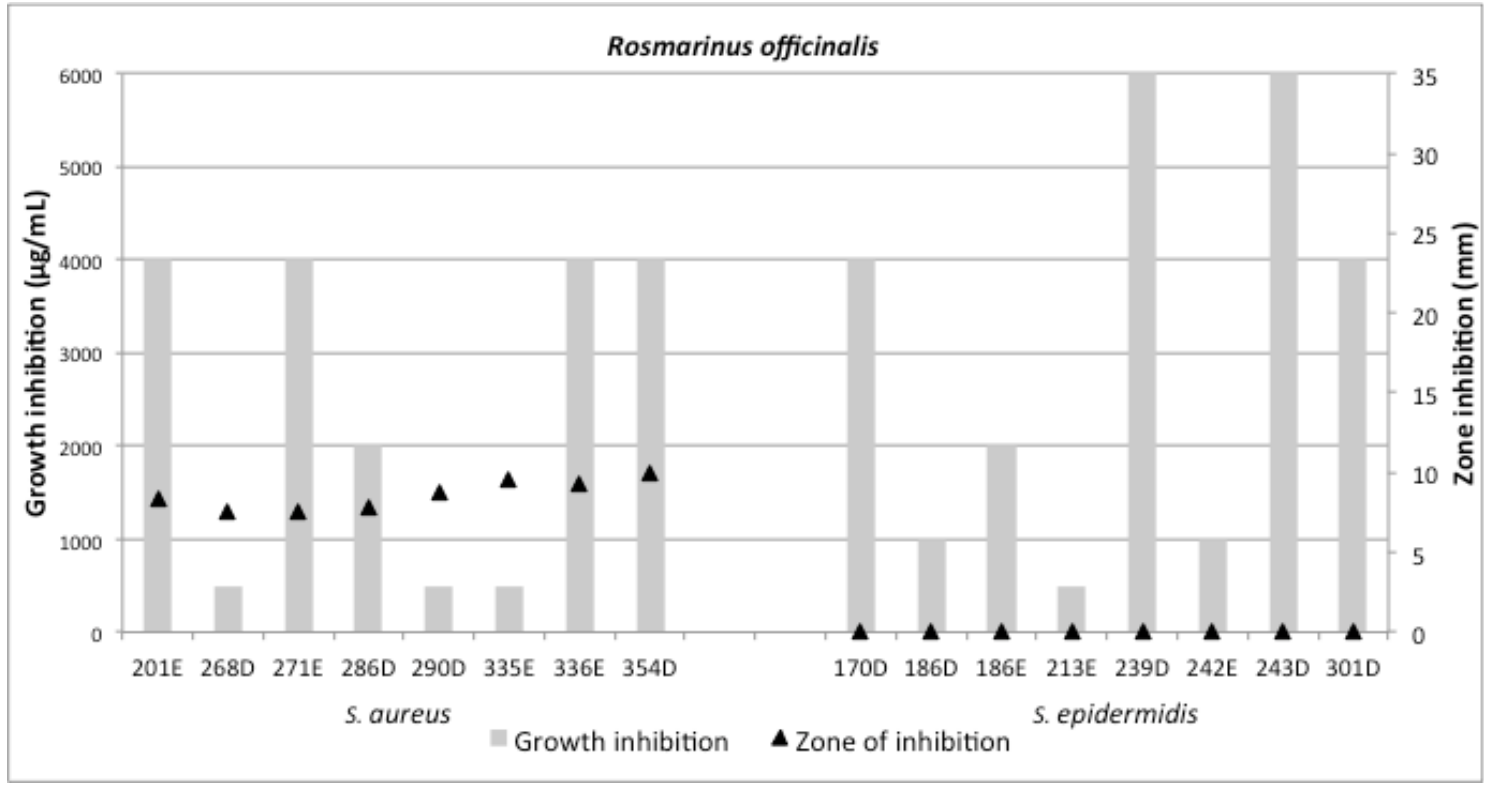

Figure 5. Rosemary antimicrobial activity according to microdilution assay and disk diffusion method

and the concentration of EO that inhibits bacterial growth (MIC).

In microdilution trial EOs showed low antibacterial activity comparatively to disk diffusion antimicrobial assays, probably due to their low solubility in liquid culture medium when added at high concentrations, which may facilitate their volatilization and resulting in loss of efficacy. Microdilution assay is widely used, as it is possible to work with very small volumes. However, this advantage can be the source of EOs inactivity towards bacteria, given that the small volume of EO used may volatilize before coming into contact with the bacteria ${ }^{29,30}$. In order to reduce the volatilization of the essential oils, the microtitre plates should be covered during the incubation.

There are many factors that may influence the results, as the EO composition, which depends 


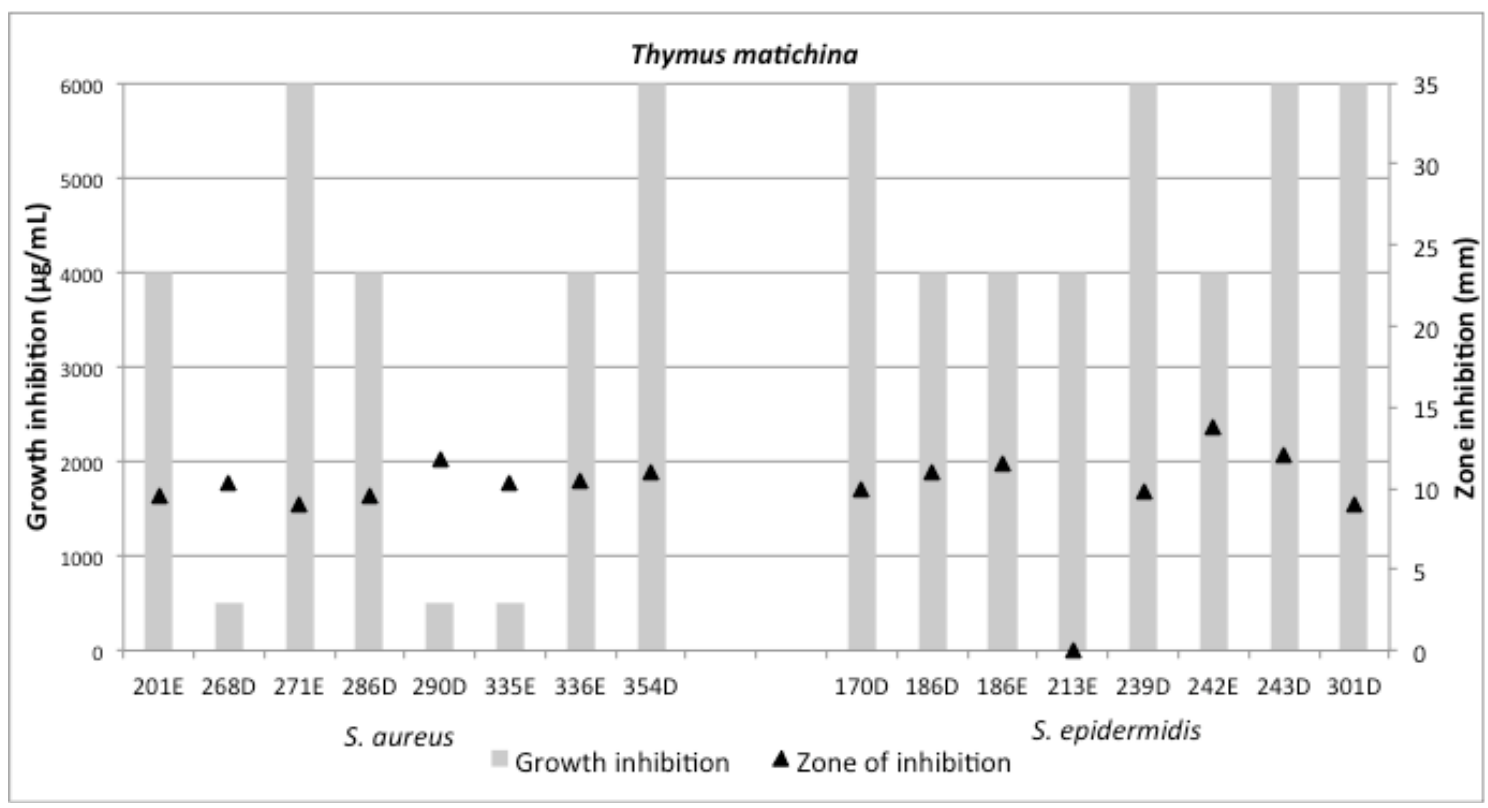

Figure 6. Thyme antimicrobial activity according to microdilution assay and disk diffusion method

on the plant growth conditions, development stage, extraction technique, fresh or dried plant material, among others ${ }^{27,31}$ and the methodology followed for testing antimicrobial activity. Although the results of the microdilution tests indicate weak EOs antimicrobial activity towards these microorganisms, according to disk diffusion assay, the four EOs were highly active against most isolates. Some authors state that the microdilution method is not appropriate to test EOs ${ }^{29,30}$. Though in some studies using inhibition zones method and MIC assays, other researchers reported remarkable antimicrobial activity of some lamiaceae EOs against staphylococci ${ }^{11,32}$.

For all cultures showing no turbidity the determination of the MBC was assessed. After incubation, bacterial growth was detected for the whole isolates, so the effect the studied EOs was bacteriostatic rather than bactericidal for the assessed field isolates.

Bacterial species used in this study are responsible for causing mastitis in sheep. These bacteria may have a relevant degree of resistance to antibiotics ${ }^{33}$, so with this study we intended to seek for a different solution for the fight against sheep mastitis. We believe that the utilization of EOs from aromatic herbs growing wild in the south of Portugal and used in Mediterranean diet may be considered for mastitis control.
Teat seal is the post-milking teat disinfection with antiseptic solutions, which is a common and excellent practice in dairy cattle ${ }^{34}$. However it is a practice rarely used in sheep milk production. The use of EOs instead of antibiotics or antiseptic solutions for this type of disinfection presents a much smaller risk for public health. The EOs used in this work were extracted from Mediterranean plants often used as condiment in human cooking so the use of these EOs as antiseptics for teat sealing seems to be a safer alternative. To increase the antimicrobial effect of these EOs the combination of two or more of these oils could be an option. Therefore further studies are needed to evaluate the antimicrobial effect and usefulness of these EO combinations as well as in vivo studies to evaluate their effectiveness.

\section{Conclusions}

Disk diffusion assay showed that the four EOs are highly active against most isolates, although microdilution tests indicated weak EOs antimicrobial activity towards tested microorganisms. Considering the problems associated with antibiotics use for mastitis control, we believe that the utilization of aromatic herbs EOs may be considered for this purpose, but further studies are needed to evaluate its usefulness as well as in vivo studies to evaluate their effectiveness. 


\section{Acknowledgements}

The authors wish to acknowledge Ervitas Catitas for the provision of Rosmarinus officinalis and Thymus mastichina EOs and Guilhermina
Pias for her help in the Microbiology laboratory. This work was funded by National Funds through FCT Foundation for Science and Technology under the Project UID/AGR/00115/2013.

\section{References}

1. Arsenault, J., Dubreuil, P., Higgins, R., Bélanger, D. (2008). Risk factors and impacts of clinical and subclinical mastitis in commercial meat-producing sheep flocks in Quebec, Canada. Preventive Veterinary Medicine. 87(3-4): 373-393.

2. Fthenakis, G.C., Jones, J.E.T. (1990). The effect of experimentally induced subclinical mastitis on milk yield of ewes and on the growth of lambs. British Veterinary Journal. 146(1): 43-49. .

3. Rovai, M., Caja, G., Quevedo, J.M., Manuelian, C.L., Saldo, J., Salama, A.A.K., Ahmed, A.K., Torre, P., Arana, I., Such, X., Leitner, G. (2015). Effect of subclinical intramammary infection on milk quality in dairy sheep: II. Matured-pressed cheese (Manchego) produced from milk of uninfected and infected glands and from their blends. Small Ruminant Research. 126: 59-67.

4. Quintana, A.M.V., Martín, M.I. (2005). Influence of somatic cell count on hard ewe's milk cheese. In: Proceedings of the 4th IDF International Mastitis Conference. Maastricht, The Netherlands. pp. 918.

5. Leitner, G., Silanikove, N., Merin, U. (2008). Estimate of milk and curd yield loss of sheep and goats with intrammamary infection and its relation to somatic cell count. Small Ruminant Research. 74(1-3): 221-225.

6. Wendorff, B. (2002). Milk composition and cheese yield. In: Proceedings of the 8th Great Lakes Dairy Sheep Symposium, 7-9 Nov., Cornell University, Ithaca, New York. pp. 104-117.

7. Queiroga, M.C. (2017). Prevalence and aetiology of sheep mastitis in Alentejo region of Portugal. Small Ruminant Research. 153: 123-130.

8. Hummerjohann, J., Naskova, J., Baumgartner, A., Graber, H.U. (2014). Enterotoxin-producing Staphylococcus aureus genotype B as a major contaminant in Swiss raw milk cheese. Journal of Dairy Science. 97(3): 1305-1312.

9. Radostists, O.M., Gay, C.C., Blood, D.C., Hinchdiff, K.W. (2000). Bovine Mastitis. In: Veterinary Medicine. 9th ed. W.B. Saunders. pp. 1452-1461.

10. Lowy, F. (2003). Antimicrobial resistance: the example of Staphylococcus aureus. Journal of Clinical Investigation. 111(9): 1265-1273.

11. Martins, M.R., Tinoco, M.T., Almeida, A.S., Cruz-Morais, J. (2012). Chemical composition, antioxidant and antimicrobial properties of three essential oils from portuguese flora. Journal of Pharmacognosy. 3(1): 39-44.

12. Lee, J.H. (2003). Methicillin ( Oxacillin ) - Resistant Staphylococcus aureus strains isolated from major food animals and aheir potential transmission to humans. Applied Environmental Microbiology. 69(11): 6489-6494.

13. Joy, B., Rajan, A., Abraham, E. (2007). Antimicrobial activity and chemical composition of essential oil from Hedychium coronarium. Phytotherapy Research. 21(5): 439-443.

14. Dal Pozzo, M., Santurio, D.F., Rossatto, L., Vargas, A.C., Alves, S.H., Loreto, E.S., Viegas, J. (2011). Activity of essential oils from spices against Staphylococcus spp. isolated from bovine mastitis. Arquivo Brasileiro de Medicina Veterinária e Zootecnia. 63(5): 1229-1232.

15. COE (2007). Council of Europe. European Pharmacopoeia. 6th ed.

16. Mottram, R. (2007). The LRI and Odour Database. (Flavour Research Group, ed.). School of Food Biosciences, University of Reading, UK.

17. Zuzarte, M., Gonçalves, M.J., Cavaleiro, C., Dinis, A.M., Canhoto, J.M., Salgueiro, L.R. (2009). Chemical composition and antifungal activity of the essential oils of Lavandula pedun- 
culata (MILLER) CAV. Chemistry and Biodiversity. 6(8): 1283-1292.

18. Cavaleiro, C., Salgueiro, L.R., Miguel, M.G., Proença Da Cunha, A. (2004). Analysis by gas chromatography-mass spectrometry of the volatile components of Teucrium lusitanicum and Teucrium algarbiensis. Journal of Chromatography A. 1033(1): 187-190.

19. CLSI. (2012). M02-A11-Performance standards for antimicrobial disk susceptibility tests; approved standard-Eleventh Edition. Clinical Laboratory Standartds Institute (CLSI)-approved Stand.

20. CLSI. (2012). M07-A9-Methods for Dilution Antimicrobial Susceptibility Tests for Bacteria That Grow Aerobically; Approved Standard-Ninth Edition. Clinical Laboratory Standartds Institute (CLSI)-approved Stand.

21. Lai, B., Teixeira, G., Moreira, I., Correia, A.I., Duarte, A., Madureira, A.M. (2012). Evaluation of the antimicrobial activity in species of a Portuguese "Montado" ecosystem against multidrug resistant pathogens. Journal of Medicinal Plants Research. 6(10): 1846-1852.

22. Arantes, S., Candeias, F., Lopes, O., Lima, M., Pereira, M., Tinoco, T. Cruz-Morais, J., Martins, M.R. (2016). Pharmacological and toxicological studies of essential oil of Lavandula stoechas subsp. Luisieri. Planta Medica. 82(14): 1266-1273.

23. Nascimento, G.G.F., Locatelli, J., Freitas, P.C., Silva, G.L. (2000). Antibacterial activity of plant extracts and phytochemicals on antibiotic-resistant bacteria. Brazilian Journal of Microbiology. 31(4): 247-256.

24. Delamare, A.P.L., Moschen-Pistorello, I.T., Artico, L., Atti-Serafini, L., Echeverrigaray, S. (2007). Antibacterial activity of the essential oils of Salvia officinalis L. and Salvia triloba L. cultivated in South Brazil. Food Chemistry. 100(2): 603-608.

25. Viuda-Martos, M., Ruiz-Navajas, Y., Fernández-López, J., Pérez-Álvarez, J.A. (2008). Antibacterial activity of different essential oils obtained from spices widely used in Mediterranean diet. International Journal of Food Science \& Technology. 43(3): 526-531.

26. Mohsenzadeh, M.M. (2007). Evaluation of antimicrobial activity of selected Iranian essential oils agains Staphylococcus aureus and Escherichia coli in nutrient broth medium. Pakistan Journal of Biological Sciences. 10(20): 3693-3697.

27. Faleiro, M.L., Miguel, M.G., Ladeiro, F., Venancio, F., Tavares, R., Brito, J.C., Figueiredo, A.C., Barroso, J.G., Pedro, L.G. (2003). Antimicrobial activity of essential oils isolated from Portuguese endemic species of Thymus. Letters in Applied Microbiology. 36(1): 35-40.

28. Cosentino, S., Tuberoso, C.I.G., Pisano, B., Satta, M., Mascia, V., Arzedi, E., Palmas, F. (1999). In-vitro antimicrobial activity and chemical composition of Sardinian Thymus essential oils. Letters in Applied Microbiology. 29(2): 130-135.

29. Delaquis, P.J., Stanich, K., Girard, B., Mazza, G. (2002). Antimicrobial activity of individual and mixed fractions of dill, cilantro, coriander and eucalyptus essential oils. International Journal of Food Microbiology. 74(1-2): 101-109.

30. Lang, G., Buchbauer, G. (2012). A review on recent research results (2008-2010) on essential oils as antimicrobials and antifungals. A review. Flavour and Fragrance Journal. 27(1): 13-39.

31. Smith-Palmer, A., Stewart, J., Fyfe, L. (1998). Antimicrobial properties of plant essential oils and essences against five important food-borne pathogens. Letters in Applied Microbiology. 26(2): $118-122$

32. Höferl, M., Buchbauer, G., Jirovetz, L., Schmidt, E., Stoyanova, A., Denkova, Z., Slavchev, A., Geissler, M. (2009). Correlation of antimicrobial activities of various essential oils and their main aromatic volatile constituents correlation of antimicrobial activities of various essential oils and their main aromatic volatile constituents. Journal of Essential Oil Research. 21(5): 459-463.

33. Onni, T., Sanna, G., Larsen, J., Tola, S. (2011). Antimicrobial susceptibilities and population structure of Staphylococcus epidermidis associated with ovine mastitis. Veterinary Microbiology. 148(1): 45-50.

34. Nickerson, C.S. (2001). Choosing the best teat dip. In: NMC-PDPW Milk Quality Conference Proceedings. pp.43-54. http://www.nmconline.org/articles/teatdip.htm. 